\title{
BURST MODE TO STRIP-MAP MODE SAR INTERFEROMETRY OF ALOS PALSAR
}

\author{
Cunren Liang ${ }^{1,2}$, Qiming Zeng ${ }^{1,2}$, Xiai Cui ${ }^{1,2}$, Jian Jiao ${ }^{1,2}$
}

1. Institute of RS and GIS, Peking University, Beijing, China 100871

2. Beijing Key Lab of Spatial Information Integration and 3S Application, Beijing, China 100871

\section{ABSTRACT}

Burst mode has been implemented in many spaceborne SAR instruments, such as Radarsat-1/2 SAR, Envisat ASAR and ALOS PALSAR, to achieve very wide swath coverage, which is the so called ScanSAR. Envisat ASAR also applies burst technique to its AP (Alternating Polarization) mode. Conventional SAR interferometry uses strip-map mode data, whereas, in our study, we try to make burst mode to strip-map mode interferometry possible, which will potentially provide many more choices of interferometry. Mixed-mode interferometry will highly improve the availability of current SAR dataset inventory, and therefore will be helpful for burst disaster monitoring, especially in the case of lacking suitable data. However, acquisitions of different modes can not be readily used for interferometry. Also to be considered is the improvement of coherence of the interferometric pair. In this paper, we propose a complete process to solve these problems. Burst mode raw data is focused using the Full-Aperture Algorithm [1]. An interferometric pair comprised of PLR (Polarimetry mode, belonging to stripmap mode) and WB1 (Wide observation mode, belonging to burst mode) mode of PALSAR is chosen to implement this process. The second problem is first analyzed theoretically and then solved by replacing the corresponding echo-lines with zero-lines. The resulting interferogram shows satisfactory fringes. In order to check the correctness of our results, the interferogram is compared with that of conventional strip-map mode.

\section{REFERENCES}

[1] R. Bamler and Michael Eineder, "ScanSAR Processing Using Standard High Precision SAR Algorithms," IEEE Trans. Geosci. Remote Sens., vol. 34, pp. 212-218, Jan. 1996.

[2] A. B. Ortiz and H. Zebker, "ScanSAR-to-Stripmap Mode Interferometry Processing Using ENVISAT/ASAR Data," IEEE Trans. Geosci. Remote Sens., Vol. 45, pp. 3468-3480, Nov. 2007.

[3] R. Bamler, D. Geudtner, B. Schattler, P. W. Vachon, U. Steinbrecher, J. Holzner, J. Mittermayer, H. Breit and A. Moreira, "RADARSAT ScanSAR Interferometry," in Proc. IEEE Int. Sympo. Geosci. Remote Sens., Hamburg, 1999, pp. 1517-1521.

[4] P. Guccione, “Interferometry With ENVISAT Wide Swath ScanSAR Data," IEEE Geosci. Remote Sens. letters, vol. 3, pp. 377-381, Jul. 2006.

[5] S. Madsen, "Estimating The Doppler Centroid of SAR Data," IEEE Trans. Aerospace Electro. sys., vol. AES-25, pp. 134-140, Mar. 1989. 
[6] D. Sandwell, B. Smith-Konter and M. Wei, "Imaging Crustal Deformation Along the San Andreas Fault System with ALOS InSAR and GPS," presented at the ALOS PI Symposium, Rhodes, Greece, Nov. 3-7, 2008.

[7] C. Liang, Q. Zeng, X. Cui and J. Jiao, “ALOS PALSAR ScanSAR Interferometry," IEEE Geosci. Remote Sens. letters, submitted for publication.

[8] I. G. Cumming and F. H. Wong, "Digital Processing of Synthetic Aperture Radar”. Norwood, MA: Artech House, 2005.

[9] M. Shimada, "PALSAR SCANSAR SCANSAR INTERFEROMETRY," in Proc. IEEE Int. Sympo. Geosci. Remote Sens., Boston, 2008, pp. IV-93-IV-96.

[10] A. M. Guarnieri, P. Guccione, P. Pasquali and Y. L. Desnos, "Multi-mode ENVISAT ASAR Interferometry: techniques and preliminary results," IEE Proc.-Radar Sonar Navig., Vol. 150, pp. 193-200, Jun. 2003. 